\section{Chronische Insomnie}

Helga Peter ${ }^{1}$ und Thomas Penzel ${ }^{2}$

${ }^{1}$ Marburg, Deutschland

${ }^{2}$ Interdisziplinäres Schlafmedizinisches Zentrum, Charité Universitätsmedizin Berlin, Berlin, Deutschland

\section{Englischer Begriff}

chronic insomnia disorder

\section{Definition}

Bezeichnung für eine länger als 3 Monate andauernde Insomnie ( „Insomnien“). In der $\Vdash$ „ICSD-3“ (2014) werden die bisherigen Insomnie-Diagnosen der ICSD-2 mit Ausnahme der Akuten Insomnie (Schlafanpassungsstörung, \KurzzeitInsomnie") in der übergreifenden Diagnose Chronische Insomnie zusammengefasst.

Siehe $>$ „Insomnien“. 